\title{
Evaluating value streams to achieve lean production in large assembly manufacturing systems utilizing virtual enterprise relationships
}

\author{
Dr. R. L. Storch, Ph.D., P. E.
}

Industrial Engineering, University of Washington

Seattle,WA98195-2650 USA

email:rlstorch@u.washington.edu

Dr. S. Lim, Ph.D.

Industrial Engineering, Gyeongsang National University

Chinju, Gyeongsang 660-701 Republic of Korea

email:sglim@nongae.gsnu.ac.kr

\section{Williamson, $M B A, P M P$}

Project Solutions

Seattle, WA 98107-4039, USA

email: matt@projectsol.com

\begin{abstract}
The objective of this paper is to evaluate value streams in large assembly manufacturing systems, such as shipbuilding, aerospace and offshore production, in order to propose a framework by which to achieve lean principles in the whole operation, including development of owner's requirements, design, material identification and handling, manufacturing, and finally delivery. The main focus will be placed on reducing the cycle time of the whole process, which will bring


maximum benefit to all customers, whether internal or external, while simultaneously producing cost reduction and quality improvement. To achieve this, the value stream along the whole operation is analyzed to eliminate all wastes (in terms of labor, material, facility, information and time). The outcome is a reorganization of the essential, value creating activities into the most efficiently sequenced and streamlined processes, producing a system of continuous flow of the processes along the value stream, in terms of both material and information flow, without any unnecessary interruption or waiting.

\section{Keywords}

\section{Lean Production, Value Stream, Supplier Chain, Large Assembly Manufacturing Systems, Virtual Enterprise, Federated Databases, Extranets}

\section{INTRODUCTION}

In a large assembly manufacturing industry, such as shipbuilding or aircraft production, massive amounts of material and information move along a vast range of activity groups, internal and external, such as owner, engineering agencies, manufacturing company, suppliers, subcontractors, governments and classification societies (inspection agencies). Hence the value stream must reflect all associated activity groups in a set. The process flow along the value stream requires just-intime arrival of needed work with associated materials and information. Material flow along the value stream needs to be continuous and balanced so that the least work-in-process inventory is maintained and the shortest cycle time can be achieved (Womack and Jones, 1996). Information flow needs to be speedy and timely so that it facilitates continuous and balanced material flow. Also appropriate capital flow based on payment conditions will facilitate desirable material and information flow.

\section{PRODUCTION ORGANIZATION}

In establishing the value stream along the whole operation, the starting key is to realize continuous and balanced flow within and between manufacturing levels from raw materials to fabrication, subassembly, main assembly, and final assembly. Then all operational activities must correspond to the manufacturing flow (Storch and Lim, 1998). Although a ship or an airplane is basically built to order as a non-repeatable product, it consists of many interim products such as parts, subassemblies, outfit units and blocks (Storch, et. al., 1995). Hence defining 
and organizing interim products appropriately and efficiently is essential to lean operation of a large assembly manufacturing system.

Each of these steps in the process may be performed by one or many different companies. "In lean supply, the entire flow from raw materials to consumer is considered an integrated whole. Interfaces between stages (i.e. between companies - suppliers and customers) are thus seen as artificial - created not as natural transformation stages in the development (or addition) of value, but as a result of the economic arrangement of assets (boundaries of firms) governed by many other factors (e.g. labor skills convenient configurations of technology, geographical location of raw materials, etc.) (Lamming, 1996)." Thus the key is to organize the process lanes and therefore material and information flows to maximize the flow of value, no matter what the company organization, or the interfaces with other companies. These value streams involve both material and information.

For continuous and balanced manufacturing flow, the entire production work should be subdivided by an appropriate productoriented work breakdown structure (PWBS) that focuses on the needed interim products.

Also efficient application of group technology (GT), supported by the PWBS, that enables repeatable manufacturing of interim products by effective parts/components family grouping, is

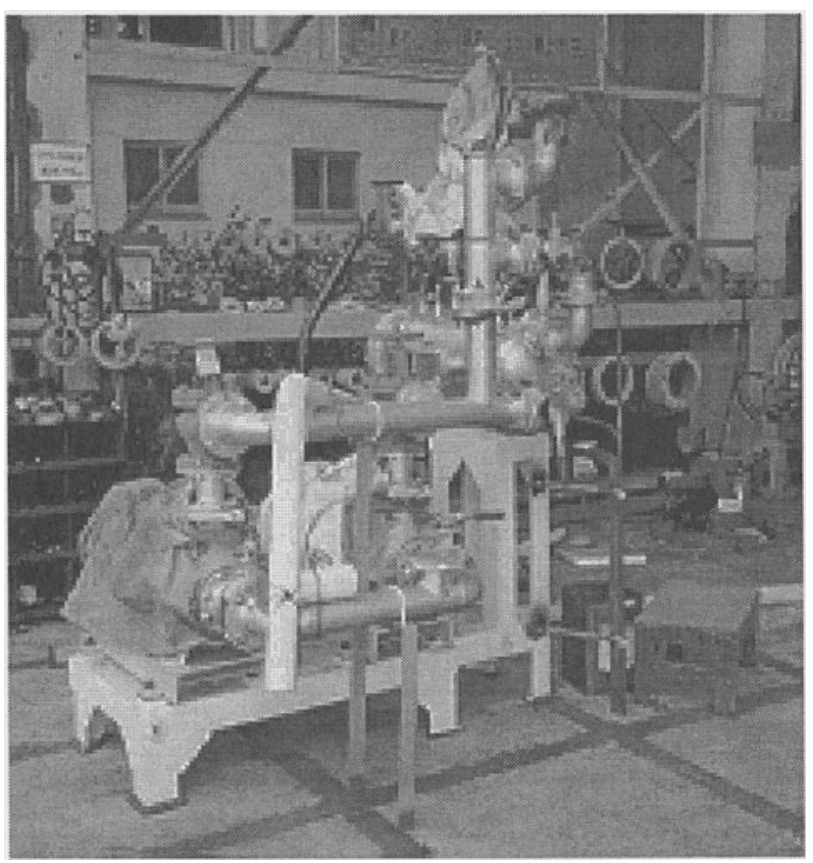

Figure 1. Typical Shipbuilding Outfit Unit required. Then all production support activities, such as design, material control and planning/scheduling need to be consistent with the associated PWBS and GT. As an example of this type of interim product, a shipbuilding outfit unit will be considered. Figure 1 is an example of a typical shipbuilding outfit unit. Note that the outfit unit contains purchased components and fabricated parts, manufactured from purchased materials.

The PWBS for outfit work in shipbuilding is shown conceptually in Figures 2 and 3. Each of the vertical lines in Figure 2 represents a typical process flow, with 
the primary flow indicated by the broad arrows. (Storch, et. al., 1995) Note that this figure is drawn from the perspective of the shipbuilder or the final assembler, and therefore does not include value streams associated with the manufacture of

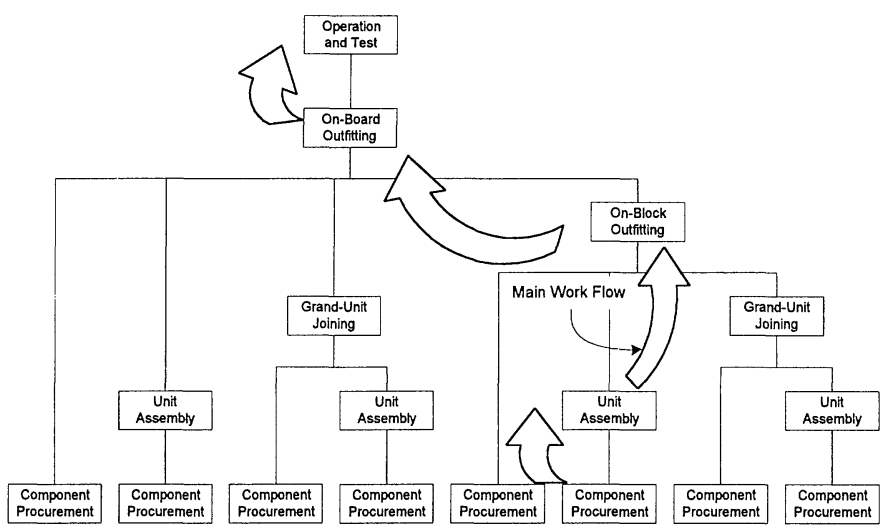

Figure 2. Zone Outfitting Method (ZOFM)

the components.

The figure does not show part manufacturing, such as the cutting, bending and flanging of pipe pieces. This manufacturing level, which can be performed by the shipbuilder or a sub-contractor, is equivalent to the component procurement level.

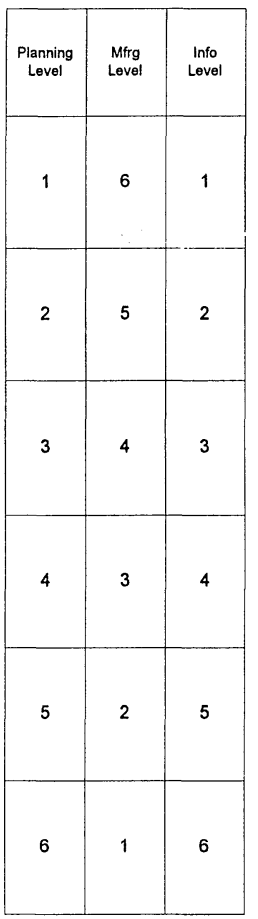

\begin{tabular}{|c|c|c|c|c|c|c|}
\hline \multicolumn{7}{|c|}{ Product Aspects } \\
\hline \multicolumn{2}{|c|}{ Zone } & \multicolumn{3}{|c|}{ Area } & \multicolumn{2}{|c|}{ Stage } \\
\hline \multicolumn{2}{|c|}{$\frac{2}{\bar{\hbar}}$} & $\overline{\overline{3}}$ & 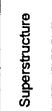 & 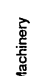 & \multicolumn{2}{|c|}{$\begin{array}{c}\text { Operation } \\
\text { and } \\
\text { Test }\end{array}$} \\
\hline \multirow{4}{*}{ 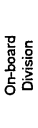 } & \multirow{4}{*}{ Nil } & \multirow{4}{*}{\multicolumn{3}{|c|}{ 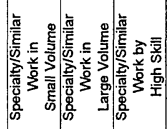 }} & Welding & Nil \\
\hline & & & & & \multicolumn{2}{|c|}{ On-closed-space Fitting } \\
\hline & & & & & Welding & Nil \\
\hline & & & & & On-open-sp & \\
\hline \multirow{4}{*}{$\frac{\text { o }}{0}$} & \multirow{4}{*}{ Nil } & \multirow{4}{*}{ 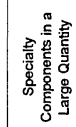 } & \multirow{4}{*}{\multicolumn{2}{|c|}{ 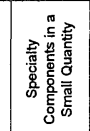 }} & Welding & Nil \\
\hline & & & & & \multicolumn{2}{|c|}{ On-fioor Fitting } \\
\hline & & & & & Welding & Nil \\
\hline & & & & & \multicolumn{2}{|c|}{ On-Ceiling Fitting } \\
\hline \multirow{4}{*}{ Unit } & \multirow{2}{*}{ Nit } & \multirow{4}{*}{\multicolumn{2}{|c|}{$\begin{array}{l}\text { Large- } \\
\text { Size } \\
\text { Unit }\end{array}$}} & \multirow{2}{*}{ Nil } & Welding & Nit \\
\hline & & & & & \multicolumn{2}{|c|}{ Joining } \\
\hline & & & & \multirow{2}{*}{$\begin{array}{c}\text { Small- } \\
\text { Size } \\
\text { Unit }\end{array}$} & Welding & Nil \\
\hline & & & & & \multicolumn{2}{|c|}{ Assembly } \\
\hline \multirow{3}{*}{\multicolumn{2}{|c|}{ 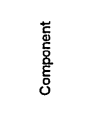 }} & \multirow{3}{*}{ 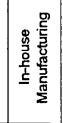 } & \multirow{3}{*}{ 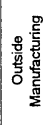 } & \multirow{3}{*}{ 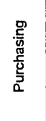 } & \multicolumn{2}{|c|}{ Palletizing } \\
\hline & & & & & Manufacturing & Nil \\
\hline & & & & & $\begin{array}{l}\text { Design and } \\
\text { Material Prep }\end{array}$ & Nil \\
\hline
\end{tabular}

Figure 3. ZOFM Classification by Product Aspect
Figure 3 shows the product aspects associated with the assembly of outfit products, from the component level to the final or completed ship system level. Each block in the figure represents a group technology work cell. (Nil implies there is no cell associated with the zone, area, stage combination). Also note that planning and information generation begin at the highest level, considering total ship systems, and progress back to the component level, developing more detail as the process 
continues. The manufacturing naturally begins at the lowest level, starting with components or parts manufacturing, and progresses through the assembly process until the total ship is completed.

In order to make value flow along the value streams, coordination within and between value streams is essential. This coordination has as a goal continuous and balanced flow. Such a system will produce the greatest value to the customer. This system is a "tightly coupled, flexible system; the high degree of coordination it requires entails rapid, frequent flows of goods and information that are likely to be expensive and difficult... (Levy, 1997)." The organization within and between companies participating in these value streams may tend to hide the total value stream. Thus a means of identifying and sharing risks and benefits among the participants is essential.

\section{VIRTUAL ENTERPRISE ORGANIZATION STRUCTURE}

Prior to the manufacture of any outfit units, or any other production work, design information must be developed and formatted to fulfill the needs of the production processes. Therefore, the PWBS, defined by the process flows of the final assembly, is employed early on in the process and communicated to all entities involved in the design and production of the product. To best support GT production processes, design occurs in three phases: Basic Design, often referred to as contract/concept design; Functional Design; and Detail Design. In the system-based functional design phase, material can be identified at a very gross level of detail; basic system component requirements can be defined. During the PWBS-based detail design phase, specific material requirements are identified and refined. Since the PWBS contains preferred production sequences and is based on the goal of achieving balanced flow within and between process lanes, schedule requirements for information and material are included. During this design phase, as material is identified, activities such as material procurement, part manufacture and unit assembly are occurring simultaneously.

As product design progresses, the numbers of partners in the virtual enterprise grow. During development of the concept business plan, the basic form of the virtual enterprise will take

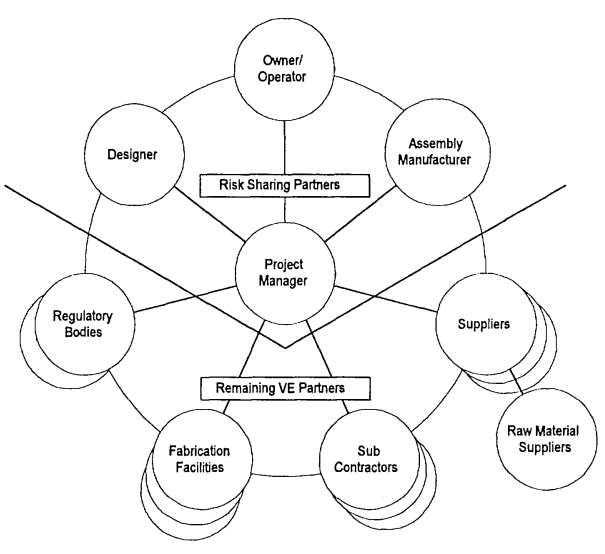

Figure 4. VE Organization Structure 
shape. At this point it will typically consist only of the risk-sharing partners of the enterprise: Owner/Operator, Designer and Product Assembly Facility. The enterprise project manager is necessary to coordinate the activities among the partners - not mediate communication (Williamson and Storch, 1998). Additionally, as the product design progresses, the project manager is responsible for identifying the remaining VE partners: suppliers, sub-contractors, fabrication facilities and regulatory bodies.

\section{INFORMATION FLOW}

In following the information flow as shown in Figure 5, the relationships between the partners in the virtual enterprise become apparent. To illustrate this process, the manufacturing of a ship will be discussed. During the basic design phase, the owner/operator teams with the designer and shipyard to define the basic requirements of the vessel. In a traditional manufacturing setting, at this point the owner would work with one designer to develop a basic design, then ask a shipyard for a design/construction bid. The shipyard, would then ask for bids from other designers or design the vessel in-house. However in the virtual enterprise, the team of principal partners (owner, designer and shipyard), along with the project manager are brought together to exploit the core competencies of each from the beginning of the process.

After the basic design is complete, the task of material identification begins immediately. The designer uses the owner specifications to query a database of common materials and components maintained by the shipyard to develop a project specific materials database. This database will be maintained and updated with project specific attributes throughout the process by the designer. From early in the functional design phase, some components can be identified to very specific levels of detail. The project manager uses this information to invite competitive bids from a select group of suppliers. The winning supplier is now a partner in the virtual enterprise. For example, based upon owner specifications, powering requirements can be defined and engine specifications can quickly be determined. The Project Manager is alerted that the engine has been sized and the engine data are pulled into the project specific database for access by engine suppliers for submittal of prospective engine design.

As the design process progresses through functional design, system components are defined in greater detail. Purchase order specifications are given to selected suppliers who, in turn, define raw material requirements. The suppliers then add component attribute information for their components into the project specific database. As the transition is made from the functional design phase into the detail design phase, production information is developed based upon the PWBS. Exact quantities and schedule requirements for material are defined and purchase order specifications are released to suppliers, and estimated and actual costs for 
construction based on the PWBS are continuously updated. Suppliers, because they have access to project specific material attributes, including schedule and outfit unit identification will, in turn palletize material for just-in-time delivery to the unit production location. Finally, throughout the process, as new material is identified, as well as corrections made to existing material records, it is fed back into both the original shipyard database of material and the project specific database.

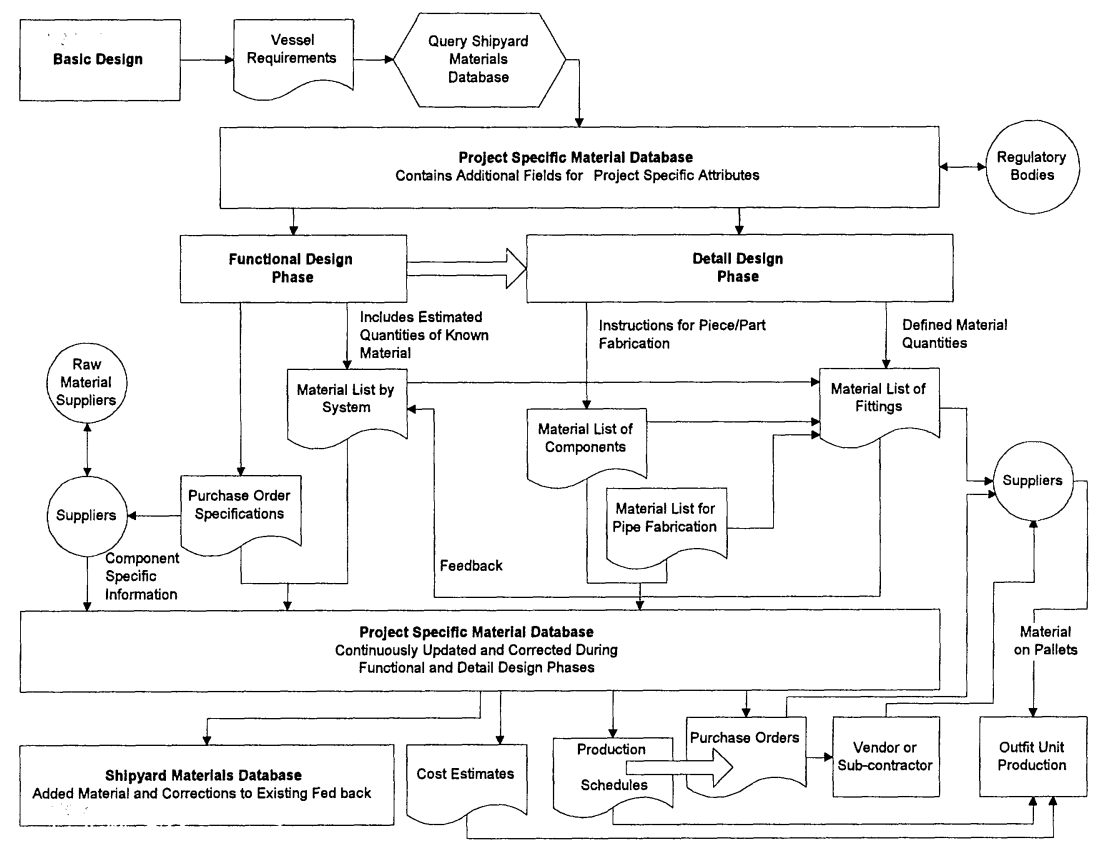

Figure 5. Information Flow for the Virtual Enterprise Value Stream

\section{INFORMATION INFRASTRUCTURE}

To facilitate speedy and timely information flow along the value stream, a specially devised mechanism for common use and exchange of information is required by the virtual enterprise. It may require the support of CALS (Computeraided Acquisition and Logistics Support, Continuous Acquisition and Life-cycle Support, Commerce at Light Speed). CALS standardizes all the needed information for product development, design, material procurement, production, marketing/distribution, and after-delivery maintenance. It supports common utilization and exchange of information among companies whether domestically or 
internationally. While CALS is the process by which this information can flow between activity groups, a solid network infrastructure must support this process to ensure that appropriate access to required information is given to each. An extranet can satisfy this need. Extranets often reside on the Internet, but rather than providing general information via open access to the general public, they provide access to specific business information via controlled, secure access to the intranets of the activity groups within the virtual enterprise (Mace, 1997).

For companies to operate effectively in this environment, three basic demands on the extranet must be satisfied: 1 . It must be able to accommodate members whose IT sophistication varies greatly. 2. It must be able to maintain an appropriate level of security, while coping with a changing pool of partners whose relationship vary in intimacy and scope. 3. It must give its members a great deal of functionality, including the capacity to transfer files between computers, the power to access and query common pools of information and the capability to utilize programs located at a remote site (Upton and McAffee, 1996).

In addition to these functional requirements on the virtual enterprise extranet, efficient transfer of information depends on accurate project-related content as well. Therefore, each organization must maintain, grant access, and control transaction processing of its own databases. By doing so, these federated databases, in that they are widely distributed and intimately connected, become the basis for the information infrastructure of the virtual enterprise (Spicknall and Bongiorni, 1997). Because each partner in the virtual enterprise allows remote access to its own database, while having access to other databases in the federation, the owner, assembly manufacturer, design organization, classification societies and suppliers/subcontractors can proceed with rapid material definition and procurement in support of the development of smaller interim products producing a constant flow of the value stream.

\section{CONCLUSION}

Large assembly manufacturers are increasingly dealing with a larger number of partners, including suppliers, sub-contractors, designers, and regulatory bodies. The multiplicity of companies and organizations can make it difficult to evaluate and optimize value streams. Additionally, issues of risk sharing amongst the companies involved must be addressed in order to optimize the entire value stream, and therefore produce the best result for the customer. The nature of large assembly manufacturing, including the large amount of information that must be developed and the tremendous quantity of material that must be identified, manufactured, marshaled, and assembled, adds to the complexity of optimizing value streams.

In order to achieve the goal, a virtual organization is proposed. The virtual organization begins with four risk sharing partners, including the owner 
(customer), the designer, the final assembler, and a project manager. The partners begin the process of designing the product, using the PWBS employed by the final assembler as a baseline. They then begin to develop a project specific database, to be shared selectively with additional partners in the virtual enterprise through an extranet. These additional partners include suppliers and sub-contractors, and also regulatory bodies and secondary customers. As the process proceeds, an opportunity is developed for all partners in the virtual enterprise to evaluate and optimize total value streams. The project specific database, to be shared with all partners, becomes the focus for interchange of information and ideas to improve balance and flow of the total value streams associated with the final product.

\section{REFERENCES}

Lamming, R. (1996), Squaring lean supply with supply chain management, International Journal of Operations \& Production Management, 16 (2), pp. $183-196$.

Levy, D. L. (1997), Lean Production in an International Supply Chain, Sloan Management Review, Winter, pp. 94 - 102.

Mace, S. (1997), The Extranet Revolution, Byte, December, pp. 65 - 66.

Spicknall, M. and Bongiorni, B. (1997), Federated Database Systems in Complex Business Environments - Utilizing Evolving Internet Technologies, University of Michigan Transportation Research Institute Report.

Storch, et. al. (1995), Ship Production, 2nd edition, Cornell Maritime Press, Centreville, MD.

Storch, R. L. and Lim, S. (1998), Improving Flow to Achieve Lean Manufacturing in Shipbuilding, manuscript under review.

Upton, D. M. and McAfee, A. (1996), The Real Virtual Factory, Harvard Business Review, July-August, pp. 123 - 133.

Williamson, M. and Storch, R. L. (1998), The Collaborative Engineering Process Within the Framework of the Virtual Enterprise, Advances in Production Management Systems - Perspectives and Future Challenges, Chapman \& Hall, London, pp. 79 - 90.

Womack, J. P. and Jones, D. T. (1996), Lean Thinking, Simon \& Schuster, New York.

\section{BIOGRAPHIES}

Richard Lee Storch is an associate professor of Industrial Engineering at the University of Washington. He holds a Ph.D. from the University of Washington, a Master's from M.I.T., and a Bachelor's from Webb Institute of Naval Architecture. His research has concentrated on productivity and quality improvement in ship 
production and large assembly manufacturing systems. He is a member of the Ship Production Committee, SNAME, IFIP WG 5.7, IIE, ASNE, and SME, and is the lead author of the text Ship Production.

Sanggyu Lim is an associate professor in the Department of Industrial Engineering at Gyeongsang National University, Korea. Previously he worked for Daewoo Shipbuilding and Heavy Machinery Ltd. and the Research Institute of Industrial Science and Technology, both in Korea. He received a Ph.D. and an M.S. from the Georgia Institute of Technology, and a Bachelor's from Seoul National University, Korea, all in industrial engineering. His research interests are facility planning and material handling systems, design and analysis of lean production systems, especially for large assembly manufacturing industries.

Matt Williamson is the owner of Project Solutions, a project management consulting firm located in Seattle, Washington specializing project management methodology development and management for engineering and technology-based organizations. He holds a BSME from the University of Utah, an MBA from City University, Project Management Professional certification from the Project Management Institute and has worked in the marine industry for 15 years. Recent research efforts have been focused on business and engineering processes for large assembly manufacturing systems. He is Vice-Chairman of the Design/Production Integration Panel of the National Shipbuilding Research Program, as well as a member of IFIP WG 5.7, PMI, SNAME, ASME and APICS. 